\title{
Necessity of Combination of Porous Ceramic Filtration and UV Radiation on Marine Bacteria Inactivation
}

\author{
Manxia Zhang ${ }^{1, a}$, Chengyu Yuan ${ }^{2, b}$, Yan Yan ${ }^{1, c}$, Wen Shi ${ }^{1, d}$ and Yimin Zhu ${ }^{1, e^{*}}$ \\ ${ }^{1}$ Institute of Environmental Pollution and Remediation, Dalian Maritime University, Dalian, China \\ ${ }^{2}$ Liaoning Ocean and Fisheries Science Research Institution, Dalian 116026, China \\ aemail: zhangmanxia@163.com, ${ }^{\text {b email: }}$ \\ yyyyyy200400@163.comlong, _ cemail: 1640698017@qq.com, e \\ email: ntp@mail.dlmu.edu.cn
}

Keywords: Porous Ceramic; filtration; UV; marine bacteria; ballast water

\begin{abstract}
A set of onshore ballast water treatment equipment utilizing micro-pore ceramic filtration (MPCF) and UV radiation (MPCF\&UV) system was designed and set up with a maximum flow rate of $80 \mathrm{~m}^{3} \cdot \mathrm{h}^{-1}$. Technical feasibilities of MPCF\&UV system were evaluated in three areas: removal efficiencies of indicator organism and oceanic bacteria, perdurability of a ceramic filter, and application on native seawater. The results showed that no indicator organism (Dunaliella) or oceanic bacteria was detected after treatment of $20 \mathrm{~L}$ MPCF and UV radiation at $1.3 \times 10^{4} \mu \mathrm{W} \cdot \mathrm{s} \cdot \mathrm{cm}^{-2}$. A $20 \mathrm{~L}$ ceramic filter can run continuously for $5.3 \mathrm{hr}$ at the flow rate of 15 $\mathrm{m}^{3} \cdot \mathrm{h}^{-1}$ before its pressure drop up to $0.195 \mathrm{MPa}$. The removal percentage of total plankton amounts were $91.9 \%$ at a flow rate of $70 \mathrm{~m}^{3} \cdot \mathrm{h}^{-1}$ by $80 \mathrm{~L} \mathrm{MPCF}$ and UV radiation at $1.3 \times 10^{4} \mu \mathrm{W} \cdot \mathrm{s} \cdot \mathrm{cm}^{-2}$.
\end{abstract}

\section{Introduction}

Since the International Marine Organism (IMO) proposed a set of guidelines and conventions for ballast water control, including Guidelines for the control and management of ships' ballast water to minimize the transfer of harmful aquatic organisms and pathogens, more and more port states attach great importance to ballast water treatment. Ships carry ballast water in transportation to ensure the maneuverability and stability [1]. Ballast water itself is harmless to environment, but it may bring large amount of organisms to destination port when deballasting. Then the live organisms may block waterways, kill local organisms, and even cause illness or death to human beings [2].

Nowadays, a series of methods have been studied on ballast water treatment onboard, like filtration, chemical treatment, UV radiation, heating, sound wave, electrolysis [3]. Currently, combination treatment with two or more methods together has been widely applied on ballast water [4]. Among those methods, filtration is regarded as the best primary technology and UV is wildely adopted as post processing, since it is effective, harmless, and well applied on bacteria inactivation in the world [5-6]. However, when it is applied on marine bacteria inactivation of ballast water, UV may lose its effects due to the existence of large amounts of plankton or other suspending substances (SS) in ballast water which can disturb the transmission of UV lights [7-8].

Therefore, a sound filtration technology, porous ceramic filtration (PCF), is applied before UV to remove SS and other plankton in advance. And the necessity of the combination of PCF and UV on marine bacteria inactivation will be argued in the paper, also the key factors that influence the inactivation efficiencies will be discussed as well.

\section{Material and Methods}

To compare UV and PCF\&UV performance on marine bacteria inactivation on seawater with high alga density, two treatment systems were setup. One is UV treatment system with two 36W UV lamps in parallel (Fig.1), and the other is MPCF\&UV system (Fig.2) with screen filter and micro-porous ceramic filter equipped before UV lamps. The screen filter is set to remove 
suspending substances (SS) in seawater before PCF to avoid blockage of PCF. The mesh size of screen filter is $1 \mathrm{~cm}^{2}$, which cannot effectively remove indicator plankton in the size of $5 \sim 20 \mu \mathrm{m}$. The porous ceramic filter plays the main role in remove plankton, with the pore size of about $5 \mu \mathrm{m}$.

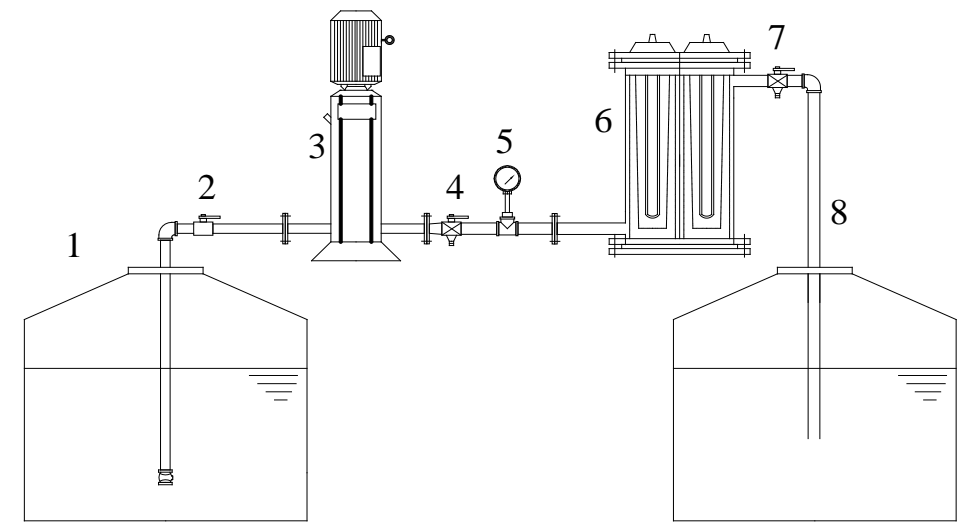

Fig. 1. Experimental equipment of UV treatment system

1)-Input water storage tank; 2)-Valve; 3)-Horizontal style pump; 4),7)-Sampling Tap; 5)-Pressure gauge; 6)-UV radiation equipment; 8)- Output water storage tank

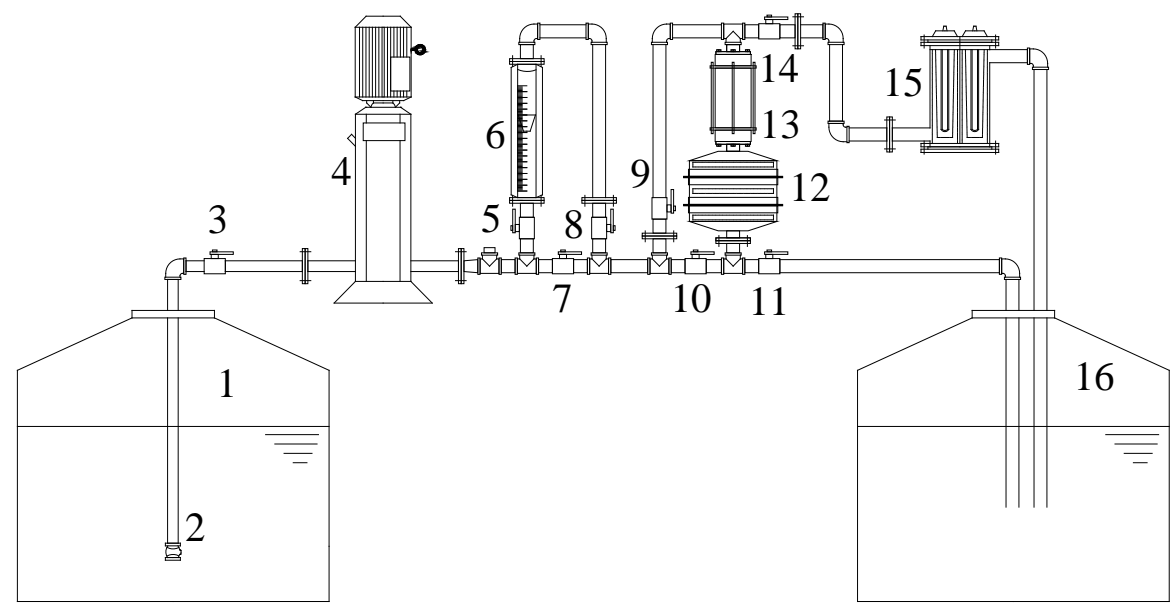

Fig. 2 Experimental equipment of PCF\&UV treatment system with screen filter

1)-Input water storage tank; 2)-Check valve; 3,5,7,8,9,10,11,14-Valve; 4)-Horizontal style pump; 6)-Flow meter; 12)-pre-filter; 13)-MPCF filter; 15)-UV unit; 16)- Output water storage tank

To detect the effects of PCF, two treatment methods were evaluated under a range of different experimental conditions. Radiation dose, algae density and algae size were identified as three key factors that may influence UV inactivation efficiency in seawater, which was set at three levels. In the tests, all the seawater was taken from Dalian Xinghai Bay (100 m away from shore). The parameters of seawater are as follows: $\mathrm{pH}$ value is $8.0 \pm 0.2$, salinity is 30 32\%o, and temperature is $18 \pm 2{ }^{\circ} \mathrm{C}$.To simulate ballast water, Platymonas subcordiformis $(10 \sim 20 \mu \mathrm{m})$, Nitzschia closterium $(10 \sim 12 \mu \mathrm{m})$ and Chlorella Vulgaris $(5 \sim 8 \mu \mathrm{m})$ were added into the water.

Marine bacteria actually can only be killed by UV radiation but not filtration. Samples were taken before and after UV radiation. To count bacteria amounts, sampling water was diluted 10, 100 and 1000 times separately. $0.1 \mathrm{~mL}$ of each dilution was spread on ZeBell2261E oceanic bacteria culture medium in a Petri dish and was cultured in the thermostat at $25{ }^{\circ} \mathrm{C}$ for $24 \mathrm{hr}$. The numbers of cultivated colonies of bacteria were counted.

Tests for three factors, UV radiation dose, alga density of seawater and alga size, were designed by a group of L9 $\left(3^{4}\right)$ orthogonal experiments, shown in Tab.1 and Tab.2. When only UV lamps are adopted in the system and no filter is set before them, flow rate is limited as well as UV dose. 
Tab.1. Orthogonal experimental scheme for marine bacteria inactivation by UV treatment

\begin{tabular}{cccc}
\hline \multirow{2}{*}{ Level } & \multicolumn{3}{c}{ Factor } \\
\cline { 2 - 4 } & UV Dose $\left(\times 10^{4} \mu \mathrm{W} \bullet \mathrm{s} \bullet \mathrm{cm}^{-2}\right)$ & Alga Density (ind./mL) & Alga Size $(\mu \mathrm{m})$ \\
\hline 1 & 1.5 & $300 \sim 500($ Low $)$ & $5 \sim 8$ \\
2 & 2.5 & $500 \sim 700$ (Medium) & $10 \sim 12$ \\
3 & 7.5 & $700 \sim 900$ (High) & $11 \sim 20$ \\
\hline Tab. 2. Orthogonal experimental scheme for bacteria inactivation by MPCF\&UV treatment \\
\hline \multirow{2}{*}{ Level } & \multicolumn{4}{c}{ Factor } \\
\cline { 2 - 4 } & UV Dose $\left(\times 10^{4} \mu \mathrm{W} \bullet \mathrm{s}^{\bullet} \mathrm{cm}^{-2}\right)$ & Alga Density (ind./mL) & Alga Size $(\mu \mathrm{m})$ \\
\hline 1 & 1.5 & $5000 \sim 10000($ Low $)$ & $5 \sim 8$ \\
2 & 1.1 & $10000 \sim 15000($ Medium) & $10 \sim 12$ \\
3 & 0.8 & $15000 \sim 20000($ High $)$ & $11 \sim 20$ \\
\hline
\end{tabular}

\section{Test results}

UV inactivation efficiencies on marine bacteria were shown in Tab.3. The results show that only 87.5\% of inactivation efficiency can be reached on seawater with alga density of 300 900 ind./mL. The ranges of results prove that $R_{A}>R_{B}>R_{C}$, which means that the influencing levels of the three factors should be listed as UV radiation dose $>$ algae density $>$ algae size.

Tab. 3. Inactivation efficiencies on marine bacteria by UV treatment

\begin{tabular}{lcccc}
\hline & UV Dose $\left(\times 10^{4} \mu \mathrm{W} \cdot \mathrm{s}^{\bullet} \mathrm{cm}^{-2}\right)$ & Alga Density $(/ \mathrm{mL})$ & Alga Size $(\mu \mathrm{m})$ & Efficiency $(\%)$ \\
\hline Test1 & 7.5 & Low & $5 \sim 8$ & 85.7 \\
Test2 & 7.5 & Medium & $10 \sim 12$ & 25 \\
Test3 & 7.5 & High & $11 \sim 20$ & 11.6 \\
Test4 & 2.5 & Low & $10 \sim 12$ & 33.3 \\
Test5 & 2.5 & Medium & $11 \sim 20$ & 9.5 \\
Test6 & 2.5 & High & $5 \sim 8$ & 7.84 \\
Test7 & 1.5 & Low & $11 \sim 20$ & 0 \\
Test8 & 1.5 & Medium & $5 \sim 8$ & 2.3 \\
Test9 & 1.5 & High & $10 \sim 12$ & 0 \\
$k_{1}$ & 40.767 & 39.667 & 31.933 & \\
$k_{2}$ & 16.867 & 12.267 & 19.433 & \\
$k_{3}$ & 0.767 & 6.467 & 7.033 & \\
Range & 40.000 & 33.200 & 24.900 & \\
\hline
\end{tabular}

By Tab.3, it can be seen that as the radiation dose reduction, or with the increase of density of algae and algae size, bacteria inactivation efficiencies decrease.

When PCF was set before UV lamps, bacteria inactivation efficiencies are obviously boosted up. Tab.4 shows that under the experimental conditions, bacteria inactivation efficiencies are range from 92.2 to $100 \%$. The ranges of results prove that $R_{A}>R_{C}>R_{B}$, which means that the influencing levels of the three factors should be listed as UV dose $>$ alga size $>$ alga density. UV dose remains the same importance as shown in UV treatment tests, while the influence of alga size is greater than the one of alga density. This is because the properties of the filter itself, which

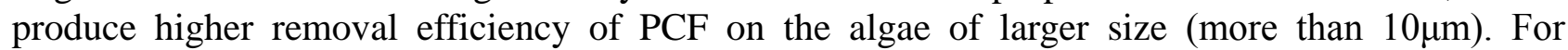
Platymonas subcordiformis (11 20 $\mu \mathrm{m}), 100 \%$ removal efficiency can be obtained by PCF. Hence, UV radiation after PCF can be greatly affected for the remained density of alga.

It is confirmed that in the PCF\&UV system, PCF performance directly affects UV inactivation efficiency. When using PCF treatment in advance, more bacteria can be inactivated by UV for a cleaner environment. UV dose is in direct proportion to bacteria inactivation efficiencies, while alga size and alga density are in inversely proportional relationship to them 
Tab. 4. Inactivation efficiencies of bacteria by PCF\&UV treatment

\begin{tabular}{ccccc}
\hline & UV Dose $\left(\times 10^{4} \mu \mathrm{W} \cdot \mathrm{s} \bullet \mathrm{cm}^{-2}\right)$ & Alga Density $(/ \mathrm{mL})$ & Alga Size $(\mu \mathrm{m})$ & Efficiency $(\%)$ \\
\hline Test1 & 1.5 & Low & $5 \sim 8$ & 98.8 \\
Test2 & 1.5 & Medium & $10 \sim 12$ & 98.1 \\
Test3 & 1.5 & High & $11 \sim 20$ & 100 \\
Test4 & 1.1 & Low & $10 \sim 12$ & 100 \\
Test5 & 1.1 & Medium & $11 \sim 20$ & 100 \\
Test6 & 1.1 & High & $5 \sim 8$ & 100 \\
Test7 & 0.8 & Low & $11 \sim 20$ & 100 \\
Test8 & 0.8 & Medium & $5 \sim 8$ & 98.0 \\
Test9 & 0.8 & High & $10 \sim 12$ & 92.2 \\
$k_{1}$ & 98.967 & 99.600 & 98.933 & \\
$k_{2}$ & 100 & 98.700 & 96.767 & \\
$k_{3}$ & 96.733 & 97.400 & 100 & \\
Range & 3.267 & 2.200 & 3.233 & \\
\hline
\end{tabular}

\section{Conclusion}

The combination of PCF and UV is necessary on marine bacteria inactivation for the large amount of plankton in seawater. By PCF treatment, alga density will reduce greatly and thus transmittance of seawater is significantly improved. Then UV inactivation ability is no longer strongly affected by algae density and higher inactivation efficiency can be achieved.

\section{Acknowledgement}

This work was financially supported by the Fundamental Research Funds for the Central Universities (3132013337-5-2) and the Scientific Research Funds of Liaoning Provincial Committee of Education (L2012180).

\section{References}

[1] Oemcke DJ, van Leeuwen J. Chemical and physical characterization of ballast water. Part 2: Determining the efficiency of ballast exchange [J]. Journal of Marine Environmental Engineering. 2003,7(1):65-76.

[2] Bax N, Williamson A, Aguero M, Gonzalez E, Geeves W. Marine invasive alien species: a threat to global biodiversity [J]. Marine Policy. 2003,27(4):313-323.

[3] Rigby G, Taylor AH. Ballast water management and treatment options [J]. International Maritime Technology. 2001,113(3):79-99.

[4] Won PG, Don LH, Seok PY, Hun HG, Park KW, Hai DL, et al. Ballast water treatment system used in ship, has central control unit that generalizes ballasting and deballasting operations of ballast tank [P]. 2014;KR2013039444-A; KR1307166-B1.

[5] Parsons MG. Considerations in the design of the primary treatment for ballast systems [J]. Marine Technology and Sname News. 2003,40(1):49-60.

[6] Yang Z, Perakis AN. Multiattribute decision analysis of mandatory ballast water treatment measures in the US Great Lakes [J]. Transportation Research Part D-Transport and Environment. 2004,9(1):81-86.

[7] Wu D, You H, Zhang R, Chen C, Lee D-J. Inactivation of Amphidinium sp. in ballast waters 
using UV/Ag-TiO2+O3 advanced oxidation treatment [J]. Bioresource Technology. 2011, 102(21): 9838-9842.

[8] You H, Du Q, Sun D. Study on ballast water treatment by using UV/O-3 process [C]. Progress of Green Oxidation/Reduction Technologies; Dalian, China; 2006. p.456-459. 